\title{
First-line health care provider performance in the management of common skin diseases using an algorithmic approach as a diagnostic tool in Kano State, Nigeria
}

\author{
This article was published in the following Dove Press journal: \\ Research and Reports in Tropical Medicine \\ 2 December 2015 \\ Number of times this article has been viewed
}

\author{
Anna Theodora Taal' \\ Erik B Post ${ }^{2}$ \\ Tijjani Hussaini ${ }^{3}$ \\ Augustin Gayus Barminus ${ }^{4}$ \\ Tahir Dahiru ${ }^{5}$ \\ 'Netherlands Leprosy Relief, \\ Amsterdam, Netherlands; ${ }^{2}$ The \\ Royal Tropical Institute, Amsterdam, \\ Netherlands; ${ }^{3} \mathrm{~TB}$ and Leprosy Control \\ Programme, Kano State, Nigeria; \\ ${ }^{4}$ State Dermatology Hospital Garkida, \\ Adamawa State, Nigeria; ${ }^{5}$ Netherlands \\ Leprosy Relief, Lagos, Nigeria
}

Correspondence: Anna T Taal

Netherlands Leprosy Relief, Wibautstraat

I 37 K, 1097 DN Amsterdam,

Netherlands

Tel +3I 205950500

Email taal.anneke@gmail.com

\begin{abstract}
Skin diseases are common worldwide, though prevalence rates in rural areas are difficult to estimate, and are primarily based on hospital studies rather than community-based studies. Primary health care providers in rural areas often lack sufficient knowledge about skin diseases, which contributes to poor skin management and subsequently causes considerable morbidity. This study looked at the performance of first-line health care providers in the management of common skin disease, using an algorithmic approach with a flowchart with diagnostic steps. As a reference standard, two dermatologists independently validated the diagnoses and treatment choices made by the providers. The performance of the algorithm was calculated in terms of the sensitivity, specificity, positive predictive value (PPV), and negative predictive value for each skin disease of the algorithm. A total of 19 patent medicine vendors and 12 traditional healers from Kano State in Nigeria diagnosed 4,147 patients with suspected skin symptoms. The most common skin disease was tinea capitis $(59.2 \%)$, and it was found predominantly among boys below 15 years of age. Together, patent medicine vendors and traditional healers had $82 \%$ of the cases correctly diagnosed, and in $82 \%$ they prescribed the correct treatment. The sensitivities varied for each skin disease from $94.8 \%$ for tinea capitis to $7.1 \%$ for contact dermatitis. The specificities varied between $87.0 \%$ and $98.6 \%$. Except for tinea capitis, lower PPVs were found for the various skin diseases when compared to earlier studies. In spite of the observed low sensitivities and low PPVs for several diseases, the algorithm seems to offer an improvement in management of common skin diseases at the peripheral level. With adaptations in training, further refinement of the algorithm and refresher training, predictive values and sensitivities can be increased.
\end{abstract}

Keywords: skin disease, community dermatology, diagnostic algorithm, patent medicine vendor, traditional healer, Nigeria

\section{Introduction}

Skin diseases are common and cause considerable morbidity worldwide. Lack of awareness of symptoms among the majority of lay people ${ }^{1,2}$ and lack of knowledge about skin diseases among first- and second-line health care providers have contributed to underestimations. ${ }^{3}$ Household surveys (including people not seeking treatment) before 2000 report point prevalence rates of $27 \%-53 \%,{ }^{2,4,5}$ while it was $62 \%-87 \%{ }^{6,7}$ after 2000 . This increase may be due to the rising industrialization in developing countries, or different definitions of skin diseases as suggested by Abdel-Hafez et al. ${ }^{6}$ In Sub-Saharan Africa, population-based studies in primary schools report point prevalence rates of $27 \%$ and $74 \% .^{8-11}$ Community-based studies by Mahé et al ${ }^{12}$ and Odueko et al ${ }^{13}$ report 
that respectively $11.7 \%$ and $9.8 \%$ of the patients consulted primary health centers with skin-related symptoms.

Different patterns of skin diseases exist within and between African countries due to climatic factors, socioeconomic conditions, hygiene practices, urban or rural areas, household density, genetics, nutritional status, and the distribution of infective agents. ${ }^{2,4,14} \mathrm{Hot}$, humid climates and rural areas for example induce fungal, bacterial, and parasitic skin diseases, while, acne and dermatitis are more common in urban areas. ${ }^{14-17}$ The global epidemiological study of Hay et $\mathrm{a}^{18}$ demonstrated that the highest prevalence rates per 100,000 population of fungal skin diseases and scabies are found in the southern Sub-Saharan Africa region and tropical Latin American region, respectively, whereas the highest prevalence rates of eczema and acne vulgaris occur in nontropical Latin America and western Europe respectively.

The pattern of skin diseases in Nigeria has altered over time, as a result of changes in socioeconomic conditions and lifestyle, improved therapies, increased exposure to irritants (rubber, cosmetics, pesticides, petrochemicals), and increased migration. ${ }^{19-21}$ Community-based studies in Nigeria have reported prevalence rates of skin diseases (or dermatophytoses alone) between $10 \%$ and $64 \%{ }^{1,13,22-27}$ The most common skin condition was fungal infections, especially tinea capitis among school-age children, especially boys, accounting for $43 \%$ of the skin diseases in the community. ${ }^{1,13,22,23,25}$ Other common skin conditions were impetigo, ${ }^{13,24}$ scabies, miliaria, pyoderma, ${ }^{13}$ and tribal marks. ${ }^{23}$

Several studies have reported a correlation between skin manifestations and HIV/AIDS, with skin manifestations in $75 \%-90 \%$ of these cases. ${ }^{28-31}$ Nigeria has more than 3.2 million people living with HIV/AIDS, of whom $12.5 \%$ are children below the age of 15 years. ${ }^{32}$ Common skin manifestations related to HIV/AIDS were pruritic papular eruption and seborrhoeic dermatitis, followed by herpes zoster, dermatophytosis, candidiasis, molluscum contagiosum, xeroderma, and drug eruptions. ${ }^{20,33,34}$ In a setting with a high HIV prevalence, such skin manifestations are predictors for the presence, progression, and severity of the HIV infection. In a study by Ukonu and Eze ${ }^{34}$ in south Nigeria, $55 \%$ of all the patients attending the dermatology clinic were HIV/AIDS patients and presented with multiple skin diseases.

Skin diseases cause considerable morbidity in developing countries, and primary health care providers are often not properly trained to recognize different skin diseases. The concept of community dermatology, developed by the Tropical Disease Research Centre in Mexico, focuses on the management of skin diseases in both rural and urban areas. The approach emphasizes the control of skin diseases, through training of health service personnel in the recognition, treatment, and control of common skin diseases; assessing the impact of skin disease on the patients' social life; and evaluating interventions. Rare diseases such as leprosy and some neglected tropical diseases with skin manifestations could also profit from this concept when integrated. ${ }^{35}$ Two studies in Kenya and Ethiopia demonstrated that community health workers are able to recognize and manage common skin diseases successfully. ${ }^{8,36}$ Mahé et al ${ }^{17}$ developed a diagnostic algorithm to support health workers to recognize skin diseases at community level in sub-Saharan countries. This algorithm consists of a flowchart that identifies the most common skin diseases, such as tinea capitis, pyoderma, scabies, superficial mycosis, and contact dermatitis, and includes the referral of suspected leprosy cases. ${ }^{37}$

Several types of first-line health providers are present in rural areas in Nigeria, allowing patients with suspected skin symptoms to choose between modern and traditional medicine. Up to $80 \%$ of African population consult a traditional healer (TH) for skin care, for reasons of being more accessible, cheaper, client centered, and culture appropriate. ${ }^{5,38,39}$ In Nigeria, the situation is similar, with more people consulting THs than patent medical vendors (PMVs). The nonpharmaceutically qualified PMVs frequently have a background in health, supply patent medicines to patients, and provide advice or guidance on the use of drugs or information about diseases. ${ }^{40} \mathrm{THs}$ rely on their knowledge of plants, transferred within the ethnic group or within the family. ${ }^{41}$ Usually PMVs and THs are not trained in managing common skin diseases. ${ }^{42}$

This study investigates if such providers in northern Nigeria can diagnose and manage common skin diseases in at least $80 \%$ of the cases, with a $\geq 5 \%$ "risk of harm" if wrongly treated after being trained in using Mahés algorithm (flowchart), modified as a patient record card. The aim was to learn lessons to refine and expand this approach.

\section{Materials and methods The flowchart}

This pilot study is based on the algorithmic approach to common skin diseases of Mahé, with the addition of pityriasis versicolor (Table 1). A flowchart follows a sequence of diagnostic steps, identifying certain objective clinical signs. Each patient with a suspected skin disease was first assessed for the presence of pyodermal signs and symptoms (Table 1, I). If the signs were present, the patient was managed and treated for pyoderma. If the pyodermal signs were absent, then the 
Table I The diagnostic items and treatment for the common skin diseases

\begin{tabular}{|c|c|c|}
\hline & Diagnostic items & Treatment \\
\hline I. Pyoderma & $\begin{array}{l}\text { - Yellow crusts } \\
\text { - Dirty looking sore } \\
\text { - Pus } \\
\text { - Blister }\end{array}$ & $\begin{array}{l}\text { - If there is an abscess: refer } \\
\text { - Mild pyoderma: antiseptic treatment ( } 10 \% \text { polyvidone } \\
\text { iodide or } 1 / 10,000 \text { potassium permanganate) for I week } \\
\text { - Severe pyoderma or after failure of local treatment: } \\
\text { erythromycin or amoxicillin (oral) in addition to } \\
\text { antiseptics }\end{array}$ \\
\hline II. Scabies & $\begin{array}{l}\text { - Itching at } \geq 2 \text { sites of the body } \\
\text { - Visible lesions on typical sites for scabies } \\
\text { (ie, interdigital spaces of hands, wrists, } \\
\text { axillae, elbows, knees, buttocks, genitalia } \\
\text { in men, breast areole in women, palms } \\
\text { and soles in children aged less than } \\
2 \text { years) } \\
\text { - Others in the same household with itch }\end{array}$ & $\begin{array}{l}\text { - If not superinfected: apply I0\% benzyl benzoate once } \\
\text { and leave for } 24 \text { hours } \\
\text { - If superinfected: I week of treatment for pyoderma, } \\
\text { followed by topical benzyl benzoate }\end{array}$ \\
\hline III. Tinea capitis & $\begin{array}{l}\text { - Scalp disorder in child aged }<15 \text { years } \\
\text { - Visible loss of hair } \\
\text { - Scaling }\end{array}$ & $\begin{array}{l}\text { - Oral griseofulvin for } 6 \text { weeks if aged }>2 \text { years } \\
\text { - Topical miconazole if aged }<2 \text { years }\end{array}$ \\
\hline IV. Superficial mycosis & $\begin{array}{l}\text { - Involvement of a skin-fold } \\
\text { - Skin lesion with circular shape }\end{array}$ & - Miconazole cream twice daily for 4 weeks \\
\hline V. Pityriasis versicolor & $\begin{array}{l}\text { - Not complete but partial pigment loss } \\
\text { - Small }(5-10 \mathrm{~mm}) \text { macules } \\
\text { - Scale on the chest, upper back, and neck } \\
\text { - Fine surface }\end{array}$ & $\begin{array}{l}\text { - Ketoconazole } 200 \mathrm{mg} \text { once daily for } 5 \text { days, plus } \\
\text { selenium, sulfide shampoo, or ketoconazole } 2 \% \\
\text { shampoo (expensive) twice weekly if many lesions on } \\
\text { the scalp }\end{array}$ \\
\hline VI. Suspected leprosy & $\begin{array}{l}\text { - Clear hypopigmented patch } \\
\text { - Reduced sensation within the patch } \\
\text { - Chronic duration }\end{array}$ & \\
\hline VII. Contact dermatitis & $\begin{array}{l}\text { - Treat and control as recommended for } \\
\text { contact dermatitis }\end{array}$ & $\begin{array}{l}\text { - Stop any former topical application and apply a basic } \\
\text { neutral ointment }\end{array}$ \\
\hline VIII. Does not fit flowchart & - Skin disease does not fit in the flowchart & $\begin{array}{l}\text { - Refer for scalp diseases in adults, chronic disorders, nail } \\
\text { diseases, acne, and tumors }\end{array}$ \\
\hline
\end{tabular}

patient was assessed for the presence of scabies signs and symptoms in the second step (Table 1, II); and so forth in subsequent steps. A patient remaining undiagnosed at the final step was considered to have a skin disease that does not fit in the flow chart and was then referred to the referral center (Table 1, VIII).

\section{Population study}

This prospective pilot study was conducted in two local government areas (LGAs) Bunkure (rural) and Nassarawa (urban) in Kano State, northern Nigeria, in 2013-2014. Sample size calculations were based on the levels of agreement between dermatologists and providers using the diagnostic algorithm, as found by Mahé et al. ${ }^{37}$ Here, the most important proportion was the "risk of harm", which was an acceptable level of $6.3 \%$ out of a sample of 1,010 patients. To demonstrate that $5 \%$ of the diagnoses/treatments have a "risk of harm" (confidence interval, 95\%; precision, 1.5\%), a sample of 811 patients was needed (EpiCalc 2000, sample/ precision/single proportion). Taking into account that there were two distinguishable groups, the PMVs and THs, a disaggregated analysis of each group was made. Hence, a two times bigger sample size was required, and a total sample of 1,622 would be sufficient. After reaching the sample size of 1,622 patients, it was decided to extend the study and gather more data. Patients presenting with a skin disease and attending the first-line health care provider for the first time were asked to participate in the study. Those who gave verbal consent were included in the study. Ethical approval had been obtained from the Kano State health authorities.

\section{The primary and secondary health care providers and validators}

A total of 40 first-line health care providers were approached to use the adapted Mahé algorithm. This study selected 20 PMVs and 20 THs (members of the Traditional Healers Association) in the two LGAs. These PMVs and THs participated in a 2-day training, given by two experienced dermatologists in Kano, for disease recognition and therapy. They were trained to use the algorithm as a diagnostic tool, 
take pictures of skin diseases, and refer any skin condition not fitting in the algorithm. To test their diagnostic skills and assess the effectiveness of the training, two tests were performed: before the training and directly after the training. The test consisted of 18 questions, with visuals about diagnosis and treatment, using the algorithm as basis. The test results improved considerably as a result of the training; PMVs improved from 38\% correct answers before the training to $86 \%$ correct answers after the training, and THs from $33 \%$ to $83 \%$. An $80 \%$ pass mark, ie, when $80 \%$ of the questions were correct, had been set as condition to take part in the pilot study. A total of 19 PMVs and 12 THs, all males with the exception of one female PMV, passed the $80 \%$ mark and were included.

Two hospitals were selected to examine the patients who were referred by the PMVs and THs, ie, the Rano General Hospital in Bunkure LGA and the Sir Mohammed Sunusi General Hospital in Nassarawa LGA. Four second-line service providers, two nurses and two community health workers, were intensively trained for 6 weeks in the recognition of a variety of skin diseases. Their knowledge and the impact of the training were also assessed by two tests, a pretest and a posttest. All the four providers had minimal background knowledge, with $1 \%$ correct at the pretest, but improved to $35 \%-56 \%$ in the posttest. The test at this level was up to the standard of medical officers, hence the rather low results.

Two dermatologists (validators), both having more than 20 years of work experience in two different teaching hospitals in Nigeria, independently validated the diagnoses and treatment choices made by the PMVs and THs. The opinion of these dermatologists, though not blind to the initial diagnoses and treatment, was considered as the reference standard.

\section{Data collection}

In practice, the PMVs and THs were asked to fill in the patients' particulars, diagnosis, and treatment based on the algorithm, and to take photos of the affected skin. Patients with incomplete records or photos of poor quality were excluded from the study.

The two dermatologists then independently reviewed the patient records and the photos The validation included correctness of diagnosis and treatment, correctness of the decision to refer, and correctness of diagnosis and treatment at referral level. The judgment of these validators held. In case of disagreement between the two validators, a third validator, a dermatologist working in a referral hospital, made the final decision.

\section{Data analysis}

The diagnostic and therapeutic data from the algorithm were compared with the validated results of the validators in order to assess the performance of the algorithm as well as the performance of the providers. The performance of the algorithm was calculated in terms of the sensitivity, specificity, positive predictive value (PPV), and negative predictive value (NPV) for each skin disease of the algorithm. Outcomes were compared to the study of Mahé et al. ${ }^{37}$ The performance of each of the providers was also calculated with the abovementioned statistical tools. Sensitivity is the proportion of true positives for a specific skin disease diagnosed by the PMVs and THs as confirmed by the validators. ${ }^{43}$ The PPV indicates the probability that the diagnosis of the specific skin disease, determined in accordance with the flowchart, is accurate for that specific disease. The NPV indicates the probability that all diagnoses other than the specific disease are accurate for other diagnoses than the specific disease. ${ }^{44}$ These statistical analyses were performed in Microsoft Excel 2010.

Two dermatologists reviewed the treatment choices made by the providers as "correct" or "incorrect". To measure the "potential harm" done by making inaccurate treatment choices by providers, the third validator valued "incorrect" cases in levels of harmfulness as described by Mahé et al. ${ }^{37}$ "No harm" was defined as "topical steroids were indicated, but not used" and "incorrect treatment, but no harm done". "Potential harm" was defined as "lack of essential medication (in case of pyoderma)" and "harmful treatment (wrong use of antibiotics)".

\section{Results}

\section{Patients}

A total of 5,097 patients with a suspected skin disease attended the PMVs and THs between October 2011 and December 2012. Among the 5,097 cases, 4,147 cases had complete records with high quality photos and gave verbal consent to participate in the study (Table 2). The remaining 950 cases had incomplete records, unreadable records, missing photos, or photos with poor quality. All patients other than those referred received treatment directly after the diagnosis was set. None of the patients recorded adverse events due to inaccurate diagnosis or treatment. Almost $70 \%$ of the study population consulted a PMV. There were significantly more males $(3,545)$ than females $(602)$, with a male:female ratio of 5.9:1. Of all cases, 75\% were below 15 years old, and $61 \%$ consulted an urban health care provider. A large proportion of the study population $(70 \%)$ had no or only primary education. 
Table 2 Sociodemographic characteristics of the study population

\begin{tabular}{|c|c|c|c|c|}
\hline & $\begin{array}{l}\text { PMV } \\
(n=2,855)\end{array}$ & $\begin{array}{l}\text { TH } \\
(n=I, 292)\end{array}$ & $\begin{array}{l}\text { Total } \\
\text { number (\%) }\end{array}$ & $P$-value ${ }^{a}$ \\
\hline \multicolumn{5}{|l|}{ Sex } \\
\hline $\mathrm{F}$ & 458 & 146 & $602(14.5)$ & \multirow[t]{2}{*}{$<0.000$ I } \\
\hline M & 2,397 & $\mathrm{I}, 146$ & 3,545 (85.5) & \\
\hline \multicolumn{5}{|l|}{ Age (years) } \\
\hline $0-4$ & 265 & 197 & $462(11.1)$ & \multirow[t]{8}{*}{$<0.000$ I } \\
\hline $5-14$ & I,796 & 846 & 2,642 (63.7) & \\
\hline I5-24 & 444 & 119 & $563(13.6)$ & \\
\hline $25-34$ & 188 & 89 & $277(6.7)$ & \\
\hline $35-44$ & 76 & 27 & $103(2.5)$ & \\
\hline $45-54$ & 35 & 5 & $40(1.0)$ & \\
\hline $55+$ & 22 & 6 & $28(0.7)$ & \\
\hline Not known & 29 & 3 & $32(0.8)$ & \\
\hline \multicolumn{5}{|l|}{ Area } \\
\hline Rural & 675 & 924 & I,599 (38.6) & \multirow[t]{2}{*}{$<0.0001$} \\
\hline Urban & 2,180 & 368 & $2,548(61.4)$ & \\
\hline \multicolumn{5}{|l|}{ Education } \\
\hline None & 961 & 208 & I,I 69 (28.2) & \multirow[t]{6}{*}{$<0.0001$} \\
\hline Primary & 1,036 & 671 & $\mathrm{I}, 707$ (4I.2) & \\
\hline Secondary & 412 & 95 & $507(12.2)$ & \\
\hline Higher & $\mathrm{I}, 0 \mathrm{I}$ & 28 & $129(3.1)$ & \\
\hline Not known & 345 & 290 & $635(15.3)$ & \\
\hline Total & 2,855 & 1,292 & 4,147 & \\
\hline
\end{tabular}

Note: ${ }^{\text {aPearson }}$ chi-square test.

Abbreviations: PMV, patent medicine vendor; TH, traditional healer; M, male; $F$, female.

\section{Skin diseases}

The main skin diseases found are shown in Table 3. Tinea capitis was the most common skin disease accounting for $59.2 \%$ of all the cases and accounted for $89 \%$ of cases in children below 15 years. Among all males and females, a higher proportion of $65 \%$ compared to $26 \%$, respectively, had tinea capitis, whereas smaller differences were found between rural (56\%) and urban (61\%) providers (ie, PMVs and THs). The second most common skin disease was contact dermatitis (7.5\%) and other variants of dermatitis, including atopic dermatitis and seborrheic dermatitis. Females (14\%) showed symptoms more often of contact dermatitis compared to males $(6 \%)$. The other skin diseases in the flowchart (eg, pyoderma, pityriasis versicolor, superficial mycosis, and scabies) had proportions between $3.0 \%$ and $5.7 \%$. In total, $0.4 \%$ of cases were referred for suspected leprosy. Rarer skin diseases found in this study were acne vulgaris, lichen simplex chronicus, papular urticaria, ecthyma, chicken pox, vitiligo, and yaws. Although this study did not record HIV infections, only $0.5 \%$ of the cases could be classified as typical HIV/AIDS-related skin diseases, including molluscum contagiosum, Kaposi's sarcoma, and herpes zoster.

\section{Performance of the algorithm: diagnosis}

The performance of the algorithm used by PMVs and THs was assessed in terms of sensitivity, specificity, PPV, and NPV (Table 4). The PMVs and THs, respectively, had 81.2\% and $82.0 \%$ of the cases correctly diagnosed and/or referred. Among the 19 PMVs and 12 THs, five PMVs and two THs performed very well and had more than $90 \%$ of the diagnoses correct, four PMVs and five THs performed well, and had between $80 \%$ and $90 \%$ correct diagnoses, whereas ten PMVs and five THs performed poorly with $\leq 80 \%$ of the diagnosis being correct (data not shown).

Overall, THs had higher sensitivities compared to PMVs, except for pityriasis versicolor (Table 4). Very low sensitivities were seen for contact dermatitis (5.5\%), superficial mycosis

Table 3 The number of skin diseases per provider, sex, type of area, and age group (as validated and corrected by the two validators and the third reviewer in case of disagreement)

\begin{tabular}{|c|c|c|c|c|c|c|c|c|c|c|c|c|c|c|c|}
\hline & \multicolumn{2}{|c|}{ Provider } & \multicolumn{2}{|l|}{ Sex } & \multicolumn{2}{|c|}{ Type of area } & \multicolumn{8}{|c|}{ Age (years) } & \multirow[t]{2}{*}{ Total (\%) } \\
\hline & PMV & TH & M & $\mathbf{F}$ & $\mathbf{R}$ & $\mathbf{U}$ & $0-4$ & $5-14$ & $15-24$ & $25-34$ & $35-44$ & $45-54$ & $55+$ & Nk & \\
\hline Tinea capitis & 1,636 & 820 & 2,299 & 157 & 893 & I,563 & 203 & 1,987 & 195 & 35 & 9 & 8 & 3 & 16 & $2,456(59.2)$ \\
\hline $\begin{array}{l}\text { Contact } \\
\text { dermatitis }\end{array}$ & 200 & 112 & 225 & 87 & 140 & 172 & 63 & 124 & 63 & 34 & 17 & 5 & 6 & & $312(7.5)$ \\
\hline Pyoderma & 169 & 69 & 172 & 66 & 107 & $|3|$ & 69 & 101 & 30 & 20 & 11 & 1 & 3 & 3 & $238(5.7)$ \\
\hline $\begin{array}{l}\text { Pityriasis } \\
\text { versicolor }\end{array}$ & 165 & 54 & 183 & 36 & 77 & 142 & 8 & 40 & 71 & 69 & 22 & 4 & I & 4 & $219(5.3)$ \\
\hline $\begin{array}{l}\text { Superficial } \\
\text { mycosis }\end{array}$ & 128 & 74 & 145 & 57 & 125 & 77 & 36 & 81 & 38 & 35 & 8 & 4 & & & $202(4.9)$ \\
\hline Scabies & 86 & 37 & 94 & 29 & 46 & 77 & 26 & 67 & 22 & 2 & 2 & & & 4 & $123(3.0)$ \\
\hline Leprosy & 12 & 4 & 13 & 3 & 8 & 8 & 1 & 6 & 5 & 3 & & & 1 & & $16(0.4)$ \\
\hline $\begin{array}{l}\text { Does not fit } \\
\text { flowchart }\end{array}$ & 459 & 122 & 414 & 167 & 203 & 378 & 56 & 236 & 139 & 137 & 34 & 18 & 14 & 5 & $58 \mid(14.0)$ \\
\hline Total & 2,855 & I,292 & 3,545 & 602 & I,599 & 2,548 & 462 & 2,642 & 563 & 277 & 103 & 40 & 28 & 32 & $4,147(100)$ \\
\hline
\end{tabular}

Abbreviations: PMV, patent medicine vendor; TH, traditional healer; $\mathrm{M}$, male; F, female; R, rural; $\mathrm{U}$, urban; Nk, not known. 
Table 4 The performance of the algorithm assessed in terms of sensitivity, specificity, PPV, and NPV of the tested algorithm for each disease and for PMV and TH separately

\begin{tabular}{|c|c|c|c|c|c|c|c|c|}
\hline \multirow[t]{2}{*}{ Disease } & \multicolumn{4}{|l|}{ PMV } & \multicolumn{4}{|l|}{ TH } \\
\hline & Se (\%) & Sp (\%) & PPV (\%) & NPV (\%) & Se (\%) & Sp (\%) & PPV (\%) & NPV (\%) \\
\hline Tinea capitis & 94.7 & 87.9 & 91.3 & 92.6 & 94.9 & 85.0 & 91.6 & 90.5 \\
\hline Pityriasis versicolor & 81.8 & 94.9 & 49.8 & 98.8 & 79.6 & 97.2 & 55.1 & 99.1 \\
\hline Scabies & 76.7 & 97.4 & 48.2 & 99.3 & 89.2 & 95.5 & 37.1 & 99.7 \\
\hline Pyoderma & 53.8 & 98.0 & 63.2 & 97.1 & 60.9 & 98.0 & 62.7 & 97.8 \\
\hline Superficial mycosis & 21.9 & 98.6 & 42.4 & 96.4 & 41.9 & 97.6 & 51.7 & 96.5 \\
\hline Contact dermatitis & 5.5 & 98.4 & 20.4 & 93.3 & 9.8 & 99.2 & 55.0 & 92.1 \\
\hline Leprosy & 33.3 & 98.3 & 7.5 & 99.7 & 50.0 & 99.5 & 22.2 & 99.8 \\
\hline
\end{tabular}

Abbreviations: PMV, patent medicine vendor; TH, traditional healer; Se, sensitivity; Sp, specificity; PPV, positive predictive value; NPV, negative predictive value.

(21.9\%), and leprosy (33.3\%) in PMVs, and for contact dermatitis $(9.8 \%)$ in THs. Low PPVs, ie, proportion of correct diagnoses made by the providers, were found in both PMVs and THs, whereas the NPVs were high. PPVs higher than $50 \%$ (more correct than wrong diagnosis) were only found for tinea capitis and pyoderma in both providers and pityriasis versicolor superficial mycosis and contact dermatitis in THs.

Among the 606 referrals, $70 \%$ were referred to Sunusi General Hospital, $15 \%$ to Rano General Hospital, and $15 \%$ to an unknown referral site. About $60 \%$ of the referral cases arrived and were examined by the second-line health care providers. The proportion of wrong diagnoses by the second-line health care providers was small (5\% in Rano and 6\% in Sunusi).

\section{Performance of the algorithm: treatment}

Table 5 shows the proportions of therapeutic agreement between the PMVs and THs and the validators. In $82 \%$

Table 5 Level of therapeutic agreement between PMVs/THs and the validators compared to the study of Mahé et al

\begin{tabular}{|c|c|c|c|c|}
\hline \multirow{2}{*}{$\begin{array}{l}\text { Level of therapeutic } \\
\text { agreement }\end{array}$} & \multicolumn{3}{|c|}{ This study } & \multirow{2}{*}{$\begin{array}{l}\text { Mahé et al's } \\
\text { study } \\
(\%)\end{array}$} \\
\hline & PMV & TH & Total (\%) & \\
\hline Complete agreement & 2,338 & 1,064 & $3,402(82.0)$ & $669(66.2)$ \\
\hline $\begin{array}{l}\text { Topical steroids were } \\
\text { indicated, but not used } \\
\text { (no harm done) }\end{array}$ & 99 & 46 & $145(3.5)$ & $206(20.4)$ \\
\hline $\begin{array}{l}\text { Incorrect treatment } \\
\text { but no harm done }\end{array}$ & 367 & 159 & $526(12.7)$ & $60(5.9)$ \\
\hline $\begin{array}{l}\text { Lack of essential } \\
\text { medication }\end{array}$ & 5 & 5 & $10(0.2)$ & II (I.I) \\
\hline Harmful treatment & 46 & 18 & $64(1.5)$ & $64(6.3)$ \\
\hline Total & 2,855 & 1,292 & $4,147(100)$ & $1,010(100)$ \\
\hline
\end{tabular}

Note: Definition of an algorithm for the management of common skin diseases at primary health care level in sub-Saharan Africa. Mahé A, et al. ${ }^{37}$ Transactions of the Royal Society of Tropical Medicine and Hygiene, 2005, adapted and reprinted by permission of Oxford University Press on behalf of Royal Society of Tropical Medicine and Hygiene. This image/content is not covered by the terms of the Creative Commons licence of this publication. For permission to reuse, please contact the rights holder. Abbreviations: PMV, patent medicine vendor; TH, traditional healer. of the cases, the validators agreed with the choice of treatment prescribed by the PMVs and THs. There were no differences found between PMVs and THs. Only two PMVs and one TH prescribed the correct treatment in $\geq 90 \%$ of their cases (data not shown). The $12.7 \%$ of "incorrect treatment, but no harm done" included cases of pityriasis versicolor receiving miconazole cream or cases of contact dermatitis receiving ketoconazole tablets for 5 days. The ten cases $(0.2 \%)$ that lacked essential treatment were all cases of pyoderma treated with ketoconazole tablets instead of antibiotics. Among the 64 cases with the risk of potential harm, 44 cases received benzylbenzoate, which may have a toxic effect for an incorrect scabies diagnosis, and one case with tinea capitis received antibiotics (data not shown).

\section{Performance of the algorithm compared with Mahé's study}

Performance of the algorithm is compared with Mahé et al's ${ }^{37}$ study (Tables 5 and 6). Overall, the sensitivities, specificities, PPVs, and NPVs in our study were lower compared to those calculated in the study by Mahé et al, ${ }^{37}$ especially the sensitivities for pyoderma, superficial mycosis, contact dermatitis, and leprosy (Table 6). This study showed a higher complete therapeutic agreement $(82 \%)$ and lower risk of potential harm (1.7\%) compared to Mahé et al's ${ }^{37}$ study $(66.2 \%$ and $7.4 \%$, respectively [Table 5]).

\section{Discussion}

This pilot study is one of the first studies investigating if firstline health care providers can identify and manage common skin diseases with an acceptable level of accuracy by using an algorithmic approach, eg, a flowchart with diagnostic steps. The providers participated in a 2-day training, given by experienced dermatologists, in the recognition and treatment of the common skin diseases, including tinea capitis, 
Table 6 The performance of the algorithm in this study assessed in terms of sensitivity, specificity, PPV, and NPV for each disease compared to the study of Mahé et al

\begin{tabular}{|c|c|c|c|c|c|c|c|c|}
\hline \multirow[t]{2}{*}{ Disease } & \multicolumn{4}{|c|}{ This study } & \multicolumn{4}{|c|}{ Mahé et al's study } \\
\hline & Se (\%) & Sp (\%) & PPV (\%) & NPV (\%) & Se (\%) & Sp (\%) & PPV (\%) & NPV (\%) \\
\hline Tinea capitis & 94.8 & 87.0 & 91.4 & 92.0 & 98.2 & 99.5 & 96.6 & 99.8 \\
\hline Pityriasis versicolor & 81.3 & 95.6 & 51.0 & 98.9 & - & - & - & - \\
\hline Scabies & 80.5 & 96.8 & 43.8 & 99.4 & $79.7-100$ & $96.9-99.5$ & $83.1-96.4$ & $97-100$ \\
\hline Pyoderma & 55.9 & 98.0 & 63.0 & 97.3 & $95.7-97.8$ & $96.5-97.9$ & $94.3-96.5$ & $97.5-98.7$ \\
\hline Superficial mycosis & 29.2 & 98.3 & 46.8 & 96.4 & 98.5 & 94.2 & 72.5 & 99.8 \\
\hline Contact dermatitis & 7.1 & 98.6 & 29.7 & 92.9 & 81.8 & 81.7 & 48.8 & 95.5 \\
\hline Leprosy & 37.5 & 98.6 & 9.7 & 99.8 & $75-100$ & $97.1-100$ & $25.6-100$ & $99.7-100$ \\
\hline
\end{tabular}

Note: Definition of an algorithm for the management of common skin diseases at primary health care level in sub-Saharan Africa. Mahé A, et al. ${ }^{37}$ Transactions of the Royal Society of Tropical Medicine and Hygiene, 2005, adapted and reprinted by permission of Oxford University Press on behalf of Royal Society of Tropical Medicine and Hygiene. This image/content is not covered by the terms of the Creative Commons licence of this publication. For permission to reuse, please contact the rights holder.

Abbreviations: Se, sensitivity; Sp, specificity; PPV, positive predictive value; NPV, negative predictive value; -, not tested.

pyoderma, scabies, pityriasis versicolor, superficial mycosis, contact dermatitis, and referral for leprosy. The outcomes of this study reflect the pattern of skin diseases within rural areas in northern Nigeria, the performance of the algorithm as a diagnostic test, and the effect of a 2-day training on the performance among PMVs and THs.

A higher proportion of tinea capitis cases was found in this study; $59.2 \%$ of the total cases, compared to the $43 \%$ of cases in previous studies. ${ }^{1,13,22,23,25}$ Similar to other studies, the majority of the tinea capitis cases were among boys below 15 years of age..$^{22,24,45-47}$ Mahé et al's ${ }^{37}$ study also revealed a lower proportion of tinea capitis $(11 \%)$, but found higher prevalence rates of pyoderma $(37 \%)$, contact dermatitis (18\%), scabies (13\%), and superficial mycosis (13\%) compared to our findings.

This study revealed a male:female ratio of 5.9:1. As several other studies have significantly lower ratios of $1.5: 1^{27,34,48}$ or even $1: 1.4,,^{26,37,49}$ our ratio is extremely high. There are different explanations for this. The finding that $59 \%$ of all the cases were tinea capitis, predominantly found among boys (93\%), may increase the ratio as it did in other studies. ${ }^{29,36,46} \mathrm{Kao}^{50}$ acknowledged this finding since he found a 5:1 male:female ratio for Microsporum audouinii-related tinea capitis. Hausa beliefs prescribe that a married woman must obtain the permission of the husband before leaving the house, and many Hausa fathers are reluctant to allow their daughters to make unescorted journeys for treatment, particularly if they consider the symptoms nonthreatening and treatable with homemade herbal treatment. ${ }^{51}$ It is highly likely that women with suspected skin problems feel uncomfortable to have pictures taken of their symptoms, or they feel uncomfortable to be examined by a male PMV or TH, or first need permission from their husbands or fathers. Therefore, since all the participating PMVs (with the exception of one) and THs in this study were men, we very likely missed a large population of female patients attending the PMVs and THs.

Various studies observed that the majority of people with a skin disorder do not seek medical advice, either because they do not see their symptoms as a problem ${ }^{5}$ or they self-medicate. ${ }^{10,52}$ In Nigeria, $65 \%$ of people self-medicate and use a form of herbal remedy. ${ }^{52}$ Since more males in this study have attended the PMVs and THs, it could be hypothesized that self-medication or herbal remedies were more successfully used in a higher number of women. The study of self-medication or herbal practices was beyond the scope of this study. It will be interesting to investigate if effective forms of herbal remedies can be added as an alternative treatment option in the flowchart.

The performance of the PMVs and THs as well as the performance of the algorithm was assessed by several statistical measures. The algorithm appeared accurate, with $82 \%$ of the cases correctly classified and $82 \%$ of the cases accurately treated. The sensitivities differed between PMVs and THs, with higher sensitivities found in THs. Furthermore, sensitivities were lower for pyoderma (56\%), superficial mycosis (29\%), contact dermatitis (8\%), and leprosy (38\%) compared to the study of Mahé et al. ${ }^{37}$ In contrast, this study showed lower "risk of potential harm" $(1.7 \%)$ compared to that of Mahé et al ${ }^{37}$ (7.4\%). Mahé et al's ${ }^{37}$ study reveals significant differences in the methodology. First, their study excluded patients with rare dermatological disorders or with obviously different symptoms than described in the algorithm. In the present study, all patients with any type of suspected skin irregularities were included, for example an amputation stump or a scar. These conditions were categorized as "does not fit flowchart", increasing the number in this category and subsequently lowering the proportions of common skin disease categories. Second, Mahé et al's ${ }^{37}$ study recruited dermatologists to verify each 
patient in person, to provide a diagnosis and to prescribe the treatment. In this study, photos of each patient were shown to two dermatologists for validation. Photos with poor quality could account for missed or inaccurate leprosy and contact dermatitis cases. Third, Mahé et al's ${ }^{37}$ study was conducted in two dermatology clinics, assuming that the health workers have regular experience in recognizing skin diseases compared to the PMVs and THs in our study. Fourth, Mahé et al's ${ }^{37}$ study and this study have a different epidemiological profile. It is known that higher prevalence rates of tinea capitis are found in field studies compared to hospital studies, because tinea capitis cases are often not referred to dermatological clinics and are found more often in rural than urban areas. The high proportion of tinea capitis cases in this study, therefore, had a negative impact on proportions of other common skin diseases. As tinea capitis cases were excluded, this influenced the performance of PMVs and THs, as the proportion of cases correctly diagnosed and correctly treated is then $65.5 \%$ and $70 \%$, respectively (data not shown).

Low PPVs were found for all common diseases except tinea capitis. A low PPV indicates that many diagnoses were false positive and subsequently led to the prescription of wrong treatment. This, in combination with the low sensitivities that were found, assumes either that the algorithm is not precise or sensitive enough, or that the PMVs and THs are not sufficiently trained in differential diagnosis. The low sensitivity for contact dermatitis is not surprising, since the label "contact dermatitis" corresponds to all diagnoses other than pyoderma, scabies, tinea capitis, pityriasis versicolor, superficial mycosis, or leprosy, according to the algorithm. This may result in more false positives. The low sensitivity for leprosy can be associated with inexperience in leprosy recognition among the PMVs and THs, due to low prevalence rates. ${ }^{20,53}$

PMVs and THs participated in a 2-day training during which they were trained in disease recognition and therapy through using the algorithm as a diagnostic tool. Only those with an $80 \%$ pass mark were allowed to participate in the study, assuming they had sufficient knowledge and practice. Overall, $82 \%$ of the cases were correctly diagnosed by the PMVs and THs, and $82 \%$ of the cases showed complete therapeutic agreement at the end of the study, which is similar, although a little higher, compared with results from the study of Mahé et al. ${ }^{37}$ Nonetheless, only nine PMVs and seven THs had more than $80 \%$ of the cases correct at the end of the pilot study. This could imply that the training was not effective enough for every provider (15 out of
31 providers) in the long-term. Regular training and a small seminar each year might be more effective ${ }^{8}$ and is likely to improve their performance. Improving information on contact dermatitis and leprosy in the training curriculum may further improve results. The algorithm needs adaptation, especially for the last two diagnostic steps. Both steps in the algorithm suggest the same. If the case is not characteristic for pyoderma, scabies, tinea capitis, superficial mycosis, pityriasis versicolor, or leprosy, it is then recommended to treat and control for contact dermatitis. This option, however, can be skipped by the health care provider, and the next step in the algorithm will be "skin disease does not fit the flowchart", referring the case to one of the referral centers. Unfamiliar or unrecognizable diseases could have possibly been entered as contact dermatitis or as does not fit the flowchart. It is most probable that this accounts for the number of contact dermatitis false negatives. To prevent this dilemma for health care providers in subsequent studies, it is necessary to include symptoms of contact dermatitis in the algorithm. The health worker can then make an informed decision as to whether or not the disease fits the description of contact dermatitis or if it fits the flowchart eventually. Another improvement for the algorithm would be to insert pictorial images of signs and symptoms. This would prompt PMVs' and THs' memory of the presentation of certain diseases, although images should not be taken as a "gold standard".

Another limitation was the validity of the reference standard. Since the two validators were not blind to the initial diagnosis and treatment choices made by the PMVs and THs, there was risk for review bias, potentially inflating the performance of the algorithm. In $10 \%$ of all the cases and in $20 \%$ of the non-tinea capitis cases, the validators disagreed with each other. Although it does not remove the review bias, it indicates that reviewers take the validation process seriously. In subsequent studies, the review bias can be avoided, by not sharing the diagnosis and treatment with the validators, but ensuring that the diagnosis is made on the basis of only the photo.

In conclusion, PMVs and THs together can recognize and manage common skin diseases, with $82 \%$ of the cases correctly diagnosed and $82 \%$ correctly treated. Only $1.7 \%$ of the cases had a potentially harmful treatment. In spite of the observed low sensitivities and low PPVs for several diseases, the algorithm seems to promise improvement in management of common skin diseases at the peripheral level. However, it should be acknowledged that 15 out of 31 providers actually correctly diagnosed less than $80 \%$ of the cases, in what 
may be termed underperformance. Furthermore, excluding the high prevalence rates of tinea capitis, performance will be lower. Further studies are needed to investigate the reasons behind differences in performance. The disappointing sensitivities in superficial mycosis, contact dermatitis, and leprosy may be avoided by adding these diseases to the training curriculum and ensuring refresher training.

\section{Disclosure}

The authors report no conflicts of interest in this work.

\section{References}

1. Ayanlowo O, Akinkugbe A, Oladele R, Balogun M. Prevalence of tinea capitis infection among primary school children in a rural setting in south-west Nigeria. J Publ Health Afr. 2014;5(1):14-18.

2. Figueroa JI, Fuller LC, Abraha A, Hay RJ. Dermatology in southwestern Ethiopia: rationale for a community approach. Int $J$ Dermatol. 1998;37(10):752-758.

3. Arthur R. Forward note. In: Orlando C, editor. A Manual of Dermatology for Developing Countries. 2nd ed. Oxford, UK: Oxford Medical Publications; 1982:vi.

4. Gibbs S. Skin disease and socioeconomic conditions in rural Africa: Tanzania. Int J Dermatol. 1996;35(9):633-639.

5. Satimia FT, McBride SR, Leppard B. Prevalence of skin disease in rural Tanzania and factors in choice of health care, modern or traditional. Arch Dermatol. 1998;134:1363-1366.

6. Abdel-Hafez K, Abdel-Aty MA, Hofny ER. Prevalence of skin diseases in rural areas of Assiut Governorate, Upper Egypt. Int $J$ Dermatol. 2003;42(11):887-892.

7. Walker SL, Shah M, Hubbard VG, Pradhan HM, Ghimire M. Skin disease is common in rural Nepal: results of a point prevalence study. Br J Dermatol. 2008;158(2):334-338.

8. Schmeller W. Community health workers reduce skin diseases in East African children. Int J Dermatol. 1998;37:370-377.

9. Murgia V, Bilcha KD, Shibeshi D. Community dermatology in Debre Markos: an attempt to define children's dermatological needs in a rural area of Ethiopia. Int Soc Dermatol. 2010;49:666-671.

10. Komba EV, Mgonda YM. The spectrum of dermatological disorders among primary school children in Dar es Salaam. BMC Publ Health. 2010;10(1):765.

11. Hogewoning A, Amoah A, Nico J, et al. Skin diseases among schoolchildren in Ghana, Gabon, and Rwanda. Int $J$ Dermatol. 2013;52:589-600.

12. Mahé A, N'Diaye HT, Bobin P. The proportion of medical consultations motivated by skin diseases in the health centers of Bamako (Republic of Mali). Int J Dermatol. 1997;36:185-187.

13. Odueko OM, Onayemi O, Oyedeji GA. A prevalence survey of skin diseases in Nigerian children. Niger J Med. 2001;10(2):64-67.

14. Havlickova B, Czaika VA, Friedrich M. Epidemiological trends in skin mycoses worldwide. Mycoses. 2008;51(4):2-15.

15. Doe PT, Asiedu A, Acheampong JW, Rowland Payne CM. Skin diseases in Ghana and the UK. Int J Dermatol. 2001;40:323-326.

16. Saliba EK, Oumeish OY, Oumeish I. Epidemiology of common parasitic infections of the skin in infants and children. Clin Dermatol. 2002;20(1):36-43.

17. Levy RM, Gelfand JM, Yan AC. The epidemiology of atopic dermatitis. Clin Dermatol. 2003;21(2):109-115.

18. Hay RJ, Johns NE, Williams HC, et al. The global burden of skin disease in 2010: an analysis of the prevalence and impact of skin conditions. J Investig Dermatol. 2013;134:1527-1534.

19. Ameen M. Epidemiology of superficial fungal infections. Clin Dermatol. 2010;28(2):197-201.
20. Yahya H. Change in pattern of skin disease in Kaduna, north-central Nigeria. Int Soc Dermatol. 2007;46:936-943.

21. Ogunbiyi AO, Daramola OOM, Alese OO. Prevalence of skin diseases in Ibadan, Nigeria. Int Soc Dermatol. 2004;43:31-36.

22. Enweani IB, Ozan CC, Agbonlahor DE, Ndip RN. Dermatophytosis in schoolchildren in Ekpoma, Nigeria. Mycoses. 1996;39:303-305.

23. Ogunbiyi AO, Owoaje E, Ndahi A. Prevalence of skin disorders in school children in Ibadan, Nigeria. Pediatr Dermatol. 2005;22:6-10.

24. Oyedeji OA, Onayemi O, Oyedeji GA, Oyelami O, Aladekomo TA, Owa JA. Prevalence and pattern of skin infections and infestations among primary school pupils in Ijesha Land. Niger J Paediatr. 2006;33(1): $13-17$.

25. Ngwogu AC, Otokunefor TV. Epidemiology of dermatophytoses in a rural community in eastern Nigeria and review of literature from Africa. Mycopathologia. 2007;164(4):149-158

26. Henshaw EB, Olasode OA, Ogedegbe EE, Etuk I. Dermatologic conditions in teenage adolescents in Nigeria. Adolesc Health Med Ther. 2014;5:79-87.

27. Onayemi O, Isezuo SA, Njoku CH. Prevalence of different skin conditions in an outpatients' setting in north-western Nigeria. Int J Dermatol. 2005;44(1):7-11.

28. Shittu RO, Salami AK, Odeigah LO, et al. Prevalence and pattern of dermatological lesions in relationship to CD4 cell counts among newly diagnosed HIV patients in Nigeria, West Africa. World J Life Sci Med Res. 2013;3(1):26-32.

29. Akinboro AO, Onayemi O, Mejiuni AD. Frequency, pattern, and extent of skin diseases in relation to CD4+ cell count among adults with human immunodeficiency virus infection or acquired immunodeficiency syndrome in Osogbo, southwestern Nigeria. Int J Dermatol. 2014;53(4):416-424.

30. Onila OA. Mucocutaneous manifestations of HIV and the correlation with WHO clinical staging in a tertiary hospital in Nigeria. AIDS Res Treat. 2014;2014:360970.

31. Nnoruka EN, Chukwuka JC, Anisuiba B. Correlation of mucocutaneous manifestations of HIV/AIDS infection with CD4 counts and disease progression. Int J Dermatol. 2007;46(Suppl 2):14-18.

32. UNAIDS. The Gap Report; 2014:1-422. Available from: http://www. unaids.org/en/resources/campaigns/2014/2014gapreport/gapreport. Accessed February 12, 2015.

33. Nnoruka EN. Skin diseases in south-east Nigeria: a current perspective Int J Dermatol. 2005;44(1):29-33.

34. Ukonu AB, Eze EU. Pattern of skin diseases at university of Benin teaching hospital, Benin city, Edo State, South-South Nigeria: a 12 month prospective study. Glob J Health Sci. 2012;4(3):148-157.

35. Hay RJ, Andersson N, Estrada R. Mexico: community dermatology in Guerrero. Lancet. 1991;337:906-907.

36. Accorsi S, Barnabas GA, Farese P, et al. Skin disorders and disease profile of poverty: analysis of medical records in Tigray, northern Ethiopia, 2005-2007. Trans R Soc Trop Med Hyg. 2009;103(5): 469-475.

37. Mahé A, Faye O, N'Diaye HT, et al. Definition of an algorithm for the management of common skin diseases at primary health care level in sub-Saharan Africa. Trans R Soc Trop Med Hyg. 2005;99(1):39-47.

38. Ryan TJ. Collaboration with traditional health practitioners in the provision of skin care for all in Africa. Int J Dermatol. 2011;50(5):567-570.

39. Naafs B, Padovese V. Rural dermatology in the tropics. Clin Dermatol. 2009;27(3):252-270.

40. Brieger WR, Osamor PE, Salami KK, Oladepo O, Otusanya SA. Interactions between patent medicine vendors and customers in urban and rural Nigeria. Health Policy Plan. 2004;19(3):177-182.

41. Mathias S, Ilyas N, Musa $\mathrm{K}$. Traditional medicine practice amongst the Takkad people of Nigeria. J Nat Sci Res. 2012;2(10):77-88.

42. World Health Organization. Epidemiology and Management of Common Skin Diseases in Children in Developing Countries. Geneva, Switzerland: World Health Organization; 2005:1-54 [WHO reference number WHO/FCH/CAH/05.12]. Available from: http://www.who.int/ maternal_child_adolescent/documents/fch_cah_05_12/en/. Accessed February 24, 2015. 
43. Altman DG, Bland JM. Statistics notes: diagnostic tests 1: sensitivity and specificity. BMJ. 1994;308:1552.

44. Altman DG, Bland JM. Statistics notes: diagnostic tests 2: predictive values. BMJ. 1994;309:102.

45. Adefemi SA, Odeigah LO, Alabi KM. Prevalence of dermatophytosis among primary school children in Oke-Oyi community of Kwara state. Niger J Clin Pract. 2011;14(1):23-28.

46. Ayanbimpe GM, Taghir H, Diya A, Wapwera S. Tinea capitis among primary school children in some parts of central Nigeria. Mycoses. 2008;51(4):336-340.

47. Soyinka F. Epidemiologic study of dermatophyte infections in Nigeria (clinical survey and laboratory investigations). Mycopathologia. 1978; 63:99-103.

48. Okafor OO, Akinbami FO, Orimadegun AE, Okafor CM, Ogunbiyia O. Prevalence of dermatological lesions in hospitalized children at the University College Hospital, Ibadan, Nigeria. Niger J Clin Pract. 2011;14(3):287-292.
49. Olasode OA, Henshaw EB, Akpan NA, Agbulu RE. The pattern of dermatoses in a skin clinic in Calabar, Nigeria: a baseline study. Clin Med Insights Dermatol. 2011;4:1-6.

50. Kao GF. Tinea Capitis. Available from: http://emedicine.medscape.com/ article/1091351-overview. Accessed February 26, 2015.

51. Stock R. Distance and the utilization of health facilities in rural Nigeria. Soc Sci Med. 1983;17(9):563-570.

52. Ajose FO. Some Nigerian plants of dermatologic importance. Int $J$ Dermatol. 2007;46:48-55.

53. Udo S, Chukwu J, Obasanya J. Leprosy situation in Nigeria. Lepr Rev. 2013;84:229-237.

\section{Publish your work in this journal}

Research and Reports in Tropical Medicine is an international, peerreviewed, open access journal publishing original research, case reports, editorials, reviews and commentaries on all areas of tropical medicine, including: Diseases and medicine in tropical regions; Entomology; Epidemiology; Health economics issues; Infectious disease; Laboratory science and new technology in tropical medicine; Parasitology; Public health medicine/health care policy in tropical regions; and Microbiology. The manuscript management system is completely online and includes a very quick and fair peer-review system. Visit http://www.dovepress. com/testimonials.php to read real quotes from published authors.

Submit your manuscript here: http://www.dovepress.com/research-and-reports-in-tropical-medicine-journal 